\title{
The Role of Municipality in Crime Prevention
}

\author{
Sara Modaberi ${ }^{1} \&$ Mahdi Momeni ${ }^{2}$ \\ ${ }^{1}$ Department of Criminal Law and Criminology, Qom Science and Research Branch, Islamic Azad \\ University, Qom Branch, Qom, Iran \\ ${ }^{2}$ Department of Criminal Law and Criminology, Payam Noor University, Tehran, Iran \\ Correspondence: Mahdi Momeni, Department of Criminal Law and Criminology ,Payam Noor University, \\ Tehran, Iran. E-mail: momeni_law@yahoo.com
}

Received: December 23, 2015 Accepted: January 15, 2016 Online Published: March 31, 2016

doi:10.5539/jpl.v9n2p18 URL: http://dx.doi.org/10.5539/jpl.v9n2p18

\begin{abstract}
Environmental factors can cause criminal impetus, motivation, realization and intention and, on the other hand, they may act as a barrier against crime realization. Right architecture designing and crime prevention initiatives in the environment are a necessary solution in crime prevention. Changes in spatial structure and environmental conditions would lead into changes in criminals' behavioral patterns. The question of this article is to clarify the role of municipality in crime prevention at urban ambiences through spatial designing. By such assumption, municipality can play a very constructive role in reducing the crimes by relying upon crime prevention strategic principles through spatial designing. Therefore, by using the principles of crime prevention theories through spatial designing, one can prevent or reduce crime and delinquency occurrence in urban environment. Thus, citizens' security will be promoted. On this basis, the origination of many criminal acts in marginal areas should be looked for in contradictory social and economic structures and their problems. In addition to play a vital role in spatial designing, Municipality would assist and provide vulnerable classes with its services such as identifying and retaining homeless people or begs. Cultural poverty, unemployment, low self - esteem, lack of infrastructural services and absconding are, inter alia, the factors which play a vital role in leading these people toward criminal acts.
\end{abstract}

Keywords: municipality, spatial designing, crime prevention

\section{Introduction}

Urbanism is goring rapidly in developing countries compared to developed ones. On this same basis, these companies are facing with more problems such as unemployment increase rate, economic and housing issues, violence, social disorders and delinquency. Delinquency is inevitable and is seen in all human societies while it is appeared with different forms in different countries. Anyhow, delinquency which injures strong feelings and collective consciousness is inevitable (Picca, 2991: 17). Crimes are not distributed similarly in all urban areas; however, they are occurred in certain locations particularly in poorest areas of the city.

As a radical component of urban structure, urban public spaces have public and social concept and are too important. Such spaces which can be a location for citizens' convenience are always considered by urban managers and planners (Hsseini, 2008). In shaping urban crimes, two factors are seem more important; the first one is relationship between citizens and urban community structure due to cultural conflicts by emigration of different people to societies. The second one relates to urban configuration, shapes of buildings and city appearances such as marginalization, geometric shapes of streets and squares, illegal accessibility to expressways, buildings crowd and semi-structured buildings (Kamyar, 2006: 47).

Since crime disorders discipline of the society and such reaction is more seen in the format of penalty, one should confess that in contrary to imagination of legal scientist in classic law school, lawmakers and the public, penalties are not panaceas which cure pains of the society and can remove crimes; therefore, it is better that to fight against crimes, we initially look for elimination and prevention of criminal stimulants; in other words, we should treat the event before occurrence. Hence, prevention is prior to treatment and preventive entities would have an excellent status in the society. Three fundamental pillars of crime prevention include "law", "social prevention" and "environmental proper planning and designs" without considering them, one cannot mitigate expectable crimes in the environment (Pourjafar et al, 2008: 75). In Criminological terms, urbanism leads to 
creation more opportunities for crime commission and lack or weak social unofficial controls would pave the way for more criminal acts (Elsan, 2008: 9).

Biravieh growth of cities would increase urban crimes. Considering such factors as current physical conditions, sound pollution, air pollution, improper environmental circumstances, and population explosion, security will be the most important factor for the residence of citizens in an urban ambience. Like other issues, urban security is the result of laws adopted in this regard (Afzali, 2013). To achieve proper crime prevention policies in urban environment, it is necessary that constructional laws and Municipality pay more attention to the importance of crime prevention and the important role of urban constructions in crime prevention since a public entity which has an important status in executing strategic plans and urban management in today societies is Municipality. Additionally, municipalities play a vital role in increasing or controlling or reducing crimes and delinquency.

On the same basis, present paper aims at studying the performance of municipality in crime prevention and at answering this question that what is the role of municipality in reducing crime and delinquency prevention?

\section{Crime Prevention through Environmental Designing (CPETD)}

A radical discussion on the role of municipalities in crime prevention is through environmental designing. Since 1970s, different insights are raised to understand the relations between place and crime. Crime prevention through environmental designing theory was coined by US criminologist (Jafari). CPTED is multilateral environmental study and designing to create desired behavior, improving efficacy and mitigating anti-social behaviors. The new approach of this field addresses designing an affective, psychological and sociological environment (Ehsani, 2004: 45). CPTED improves public security and mitigates crime commission fear by designing and managing physical environment of constructions and residential places. Also, it fosters such efforts through public awareness of police and police patrols and improves cooperation between police and the public to prevent crime commission and social disorders.

\subsection{Theories}

Concerning the determining role of urban constructions in creating security and crime prevention, various theories are provided and we introduce the most important ones here:

1) The theory on using old pattern of streets design: John Jacobs criticized the separation of lands used in different parts of cities as well as concentration on using special centers: Regions like urban, cultural and shopping, etc. (Jacobs, 1961, 125). He asserted that new cities can be successful only if they follow streets old patterns with complicated usages and people as natural traits of streets can dominate it. It should be possible that one can see streets from buildings; streets that are toward buildings. In public places like streets and parks are used too much, street crimes occurrence is more likely. Therefore, sidewalks should have repeatedly walking population and perspectives which look at streets permanently. This can be shaped by increasing the number of shops, restaurants and buildings that are used publicly.

2) The theory of crime relationship with population crowd: according to this theory, crimes increase relate directly to population crowd increase. In 1968, Angels proved the relation between crime and population crowd in California street crimes. He believed in crime increases and the crowd of activities in urban streets (Kalantary, 2001: 80).

3) Crime distribution theory: Patricia and Brantingham found that half of delinquents live in one region like a big city or special area latently. They concluded that there are remarkable differences between special areas and number of crimes. Also, they found that designing neighborhood design impacts on the results of the number and distribution of crimes.

4) Criminal travel theory: this insight is based on the study of two factors of place and distance of travels by criminal to commit their offences. In his research, Tuner found that criminal travels are mitigated by getting far from criminals' residence. In other words, a reverse link is seen between the number of criminal travels and distance from criminal residential life (Kalantari, 2001: 82 - 84).

5) People and environment management theory: in his book "crime free design", Ron Clark (1980: 143) provided different strategies on crime prevention. In next researches, he addressed discussions on natural supervision. Many recommended items include using space and management of people and environment which is beyond designing and planning. This list outlines themes which mitigate crime. Hence, one can understand that through environment and people management, resolving such problem will be simpler, easier and easier than a stronghold-type ambience. 
6) Perspective improvement theory: by studying different projects, Granland suggests that designing should be progressed traditionally. He indicated that external spaces that are organized well and have better perspective than entering door can prevent crime occurrence and destruction better (Rahmat, 2006: 8).

7) Neighborhoods miniaturization theory: it was raised by Gary Cleveland in 1972. He studied environment construction as the first step to establish sustainable and healthy communities. He asserts that neighborhoods should be miniaturized. In this way, one can improve local, social and economic communications. Constructing smaller neighborhoods would improve social links. According to him, planners can groom the skills of constructing smaller neighborhoods skills without any prejudice (Gary Cleveland, 1976: 176 - 189).

8) Architecture as behavior determining factor theory: as the member of land research of London King University, Alice Klemen played an important role in advancing crimeless designing. According to him, architecture determines behavior rather than impacting on it. In his opinions, he criticized architectures and designers on height buildings. According to him, these constructions were neither economic nor right behaviorally (Rahmat, 2006: 10).

9) Space combination theory: Bill Hillier studied the modification of urban areas through urban designing. Space combination is the tool to expound social insights in relation to human behavior and space usage. Crimes are occurring in silence places with lower links to other locations. In locations where there is no high difference between private and public spaces with low natural monitoring, crime commission is further. There is a direct link between the homes that have caused blank spaces by their progresses in sidewalks and there is crime fear in the movement of pedestrians (ibid: 78).

10) Broken windows theory: George Killing and James Wilson in their well-known article in Atlantic Monthly Journal in March 1982 titled "broken windows: police and security of neighborhoods" believed that small negligence like leaving a broken window indicates the message of fall and indifference which would encourage antisocial behaviors which would finally lead into crime. This theory emphasizes on the vital importance of environmental protection as a physical indicator for correlation as well as social integration and social control unofficially.

11) Crime prevention by environmental designing: it was coined by Jeffrey in crime prevention article. It is based on designing and management of environment configuration to mitigate crime commission opportunities. Before committing a crime, criminal and delinquents enter a rational decision making process. In fact, crime prevention by environmental designing theory is the proposal of environmental planning and redesigning methodology by which architects can mitigate the fear of crime and delinquency and improve life quality (Ghalibaf, 2010: 25).

12) Defensible space theory: in 1972, Newman raised "defensible space" theory. By analyzing effective social and configuration factors in crime, he concluded that there is a relationship between different kinds of configuration designing and crime patterns (Salehi, 2009: 130) he concluded that crime rate in separated spaces are far from public inspection while in locations where there is high supervision by local people and high correlation feeling, crime occurrence is too lower. On this basis, designing can help a delinquent in selecting the location and type of crime commission and or hidden it. For Newman, defensible space is an alternative term for a range of mechanisms, symbolic borders and real borders that have defined penetration regions and improve monitoring opportunities and they are combined to be controlled by residents.

13) Rational choice theory: the theoretical roots of crime prevention insight by environmental designing and management are extracted from rational choice theory. This theory analyzes trends by which potential criminals and delinquents select their targets. New rational choice insight is focused on decision making process by which criminals and delinquents determine final location to conduct their steals. To this end, environment is considered as tools which already help criminals to select a proper location for their crimes.

14) Social disorder and crime theory: according to this attitude, increasingly social disorder is the result of excessive increase in crimes. Shaw and Mac identified three social factors which reduce social organization. These three factors include low economic status, tribal heterogeneity and residential mobility. Additionally, Sampson and Grows defined familial disorder as the reason of social disorder.

15) Crime generating locus theory: it expresses a location with high rate of crime. Its scope is a part of city, a small neighborhood or some adjacent streets and even a home or residential complex (Kalantari, 2001: 85). Delinquency Mitigation Center affiliated by UK Ministry of Interior has defined such locus as a geographical area in which crime occurrence is higher than average or is more focused that total crime distribution in total 
area. Crime generating locus is a determined scope which covers a high share of total crimes in studied area (Kalantari and Tavakoli, 2007: 4).

\subsection{CPTED Principles and Strategies}

Crime prevention principles trough CPTED involve objective efforts like buildings control ways and special environmental monitoring. It also includes environmental fostering and increasing the feeling of security in people's life and work environments through activities which emphasize on environmental unofficial control (Felisner, 2004: 82).

Crime prevention through CPTED has six pillars:

1) Scope (territory) determination

2) Monitoring (either official or unofficial)

3) Entrance control

4) Image and maintenance

5) Making crime target hard

6) Procurement

a. Scope (territory) determination: undefined and indefensible spaces create the feeling of making harassment and encourage crimes. When scopes are clear and separated, people would open their eyes and react (Bahrayni and Tajbakhsh, 1998: 25). Scope factor is the sign of ownership or supervision which would lead into monitoring by residents and prevent criminals to commit crimes intangibly by alarming them who are stepping into people's privacy. Defining the borders of controlled spaces need a general law by which the territory of people is defined for their ownership. Such definition can be physical or symbolic. Fences, bushes and signs can provide a plausible definition on borders. These radical principles are based on the fact that a rational person should be able to diagnose transfer from public space to private one. Transferring spaces should show transition for general space (transitional filters) to semi-public and from semi-private to private spaces through signing them explicitly.

b. Monitoring or supervision: physical designing has the capability to improve the opportunities of residents' unofficial and natural monitoring (Child, 2000: 53). The main aim or supervision is not to escape obtrusive; rather, the main aim is to monitor him precisely so that he cannot annoy anyone. Monitoring can be seen as a part of neighborhood potential protection. In the case that criminal imagines that by crime commission, he is exposed by monitoring event though it is not in reality, it will be less likely that he commits a crime since in the process of transition from thought practice, he would measure the benefits and risks of crime commission. He knows that in this neighborhood, the possibility of intervention by residents, police and arrest is too high due to potential monitoring so he will refuse crime commission. The principle of "seeing and being seen" in one of the most traditional and explicit methods of crime commission. The feeling of natural monitoring has more impact that real monitoring. The existence of such monitoring is as effective as mechanical one. Windows, clear and transparent sight line and other natural techniques are too effective in crime mitigation.

c. Entrance (accessibility) control: accessibility control is a main concept of this theory which focused on mitigating criminal opportunities. Such reduction through prevention access to potential targets is realized to increase the risk of arresting and efforts to commit crimes. Studies indicate that those regions with irregular entrances and accessibility experience more crimes than regions with limited entrances and accessibility.

d. Space image and maintenance: defensible theory emphasizes that security and livability in a space depends on the understanding and image by residents and adjacent areas. If residents have a bad image of that area, it is more likely to commit crimes there. Effective and fruitful usage of space would mitigate risk rate and risk feeling. In contrary, criminals would feel more risks in such area since the rate of monitoring and intervention is more likely (Ghurchi Beigi, 2007: 153). On the other hand, any crime demands its own environmental security; therefore, it is too important to identify the secure environment for that crime and to finds ways to deprive objective environmental security especial a mental environment. Here, security means the mental and inner context of the offender which destroys inner barrier of crime and lets him to plan for committing a crime and facilitates utilizing tools and equipment. Crime environment insecurity especially mental one is too different in criminals' withdrawal. Therefore, one should pay attention to the categorization of criminals. Making the environment of crime insecure for teenager, youth, adults, experienced or new criminals and occasional criminals are different (Suleimanpour, 2005: 130).

e. Making crime targets hard: it is the most traditional way of crime prevention and a main element of this theory. Its aim is to improve physical security of crime targets to make it harder to criminal to commit offences 
(Najafaiabrandabadi and Hashem Beigi, 1998: 323). Making crime targets hard in buildings means to improve security standard which would make criminals far from buildings. In other words, it means to design targets and objects which are usually destroyed and stolen so that they can resist against crimes and can be protected from destruction or steal (Morteaei, 2002: 14).

f. Logistics: it includes designs to encourage residents to use and attend in public spaces further. In other words, it is to put insecure activities in locations with high activities and paramount opportunities of supervision. On the other hand, secure activities act as a magnitude which gathers the residents of a neighborhood which would reduce the attendance of offenders. Putting secure activities in insecure locations: in this way, one can overcome the problems in universities, parks, offices and institutes. Secure activities would act like a magnet and attract ordinary users. It would inspire other ordinary users that they are protected while it alarms abnormal users that they are exposed by risk or intervention. Putting insecure activities in safe locations: conducting vulnerable activities near windows of residential places and/or in an area with excessive control would help to overcome the risks and would improve residents' security feelings. Building and space would not be in separated locations and, in fact, they should be designed so that some feels that he is captured in a location and in the case of aid, no one can help him/her (Ghorchi Beigi, 2007: 154).

\section{Crime Prevention in Laws and Machinery of Municipalities}

\subsection{Crime Prevention in the Context of Municipalities'Laws}

Concerning crime prevention in Iranian legal system, one should say that before submitting crime prevention act in 2005, crime prevention was not executed systematically and there was no certain organization to manage and implement crime prevention. Many organizations were performed disperse initiatives in this regard. The most important legal initiatives conducted so far on crime prevention include crime prevention law (2015); the law on Establishing Urban Construction and Architecture Higher Council (1972); Article 100 of the Law of Municipalities (1965); National Land and House Statute (2008) and the Fourth Economic, Social and Cultural Plan of the I. R. of Iran (2004).

Crime prevention act is the first act submitted to Parliament in this regard and a positive step to operationalize crime prevention mechanism in Iran. This act discusses on crime prevention management and structure. Achieving a proper structure to operationalize crime prevention in Iran is the most important concern and the most basic challenge.

In the act approved by Parliament, Judiciary Head is assigned as the Head of Prevention Higher Council. It seems that in Iranian current structure, one cannot consider crime prevention as an exclusive task of Judiciary since most crime prevention practical tools are in Executive and practically, Judiciary cannot be successful without the help of Executive Power.

In approved text by Parliament submitted to Guardian Council, article 3 has considered seven tasks for Crime Prevention Higher Council: determining national crime prevention strategies, policies and national plans; clarifying the scope and limitation of tasks for each prevention entity; adopting strategic initiatives to prevent trial prolongation and rapid verdict enforcement; adopting proper initiatives for coordination and cooperation development among organs responsible for prevention; necessary measures to expand prevention culture and contribution by nongovernmental organization; assessing the results, proposing needed budgets and adopting proper measures to use existing resources optimistically. Today, in crime prevention policies especially in a multi-entity and inter-organizational policy, assigning crime prevention local tasks to lower levels of the society namely contribution by people along with official and governmental agencies are too important. On the other hand, experience has proved that crime prevention is has few or no impact through general, steady and similar plans and strategies without flexibility and considering local needs and requirements. Local approaches are effective ones namely an approach drawn by considering the needs of any region and neighborhood, types of crime and criminals, region's criminal image and other cultural requirements.

In article 1 of the law on Establishing Iranian Urban Building and Architecture Higher Council (1972), lawmaker considered the aim of this council to harmonize urban building plans in order to create a better environment for people, to promote Iranian architecture art, to respect different national and traditional architecture styles, to provide relevant norms, to consider modern scientific and technical methods and to find proper constructional principles in different parts of the country through paying attention to climate conditions, lifestyles and local requirements. Hence, hence the Council can determine norms and rules by considering crime prevention management principles in line with article 4 of abovementioned law: "approving urban building measures, norms and recipes." Along with research and executive activities, adopting urban building principles and urban designing in a short term plan can be a task conducted by the Council toward crime prevention management 
(Akhundi, 1996: 98). According to article 100 of the Law on Municipalities (1965), a Municipality can prevent construction of building without relevant licenses. To respect right principles of designing, one can announce necessary the certification of respecting crime prevention principles. National Land and House Statute Organization (article $6(4,15,17,18$ and 19) indirectly discuss on crime prevention through urban building. According to article 97 of National $4^{\text {th }}$ economic social and cultural program of I. R. of Iran, the government is obliged to prepare social harm reduction comprehensive plan. Hence, we observe that crime prevention management is a radical point in this law.

\subsection{Crime Prevention in the Structure of Municipality Machinery}

Efforts on crime prevention are not limited to Judiciary's authorities and other governmental organs including municipalities can play a vital and constructive role in urban management. The performance of municipalities in organizing margins of cities and prevention planning would prohibit the concentration of criminals and not manifestation of potential criminals' individual capabilities due to being influenced by social environment. Charles Abrahams defines margin as a process of capturing different urban areas in order to have a house. Generally speaking, Marginalization includes all people who live in economic limit of a city but are not attracted by urban economy. In his research, Shokuhi asserted that in developing nations like Iran that are in a special stage of transition, marginalization in cities means a regions of old residential units with deficient equipment in the margins of cities, domination of poverty culture in the region, mass separation of villagers from urban community, towns attached to cities with low resistant materials, emigration and residence of some villagers in the margins of cities. As a result, marginalization concept includes all people who live in spatial, economic, social and cultural scope of a city while their residence and subsistence are totally separated from urban community and are not synchronized with urban community.

Overall, there are different reasons which influence on marginalization such as low level of household income and high rate of land price, official construction cost, high rents, lack of land and poverty would escape people from their homes toward cities and long cost of living in cities would yield to marginalization. Another factor is to segment lands which improve the price of land and low income persons would gradually lose the power of buying lands. Emigration is either from villages and small cities to bigger ones of from cities to marginal areas. Obviously social and living environment impacts on crime occurrence highly. This is proved and accepted by criminologists, sociologists and jurists. Theories and results of conducted studies indicate the impact of environment in crime occurrence. Criminal acts upon marginalization include steal, intentional kill, collective conflicts, threats against public health and environmental pollution and illicit drugs/alcoholic drinks addiction and dealing.

A few people may imagine that improper homes can create crime. The reality is that countless individuals believe that the root of deviations should be looked for in improper residential units. In all hierarchical societies, criminals belong to improper and inferior locations more than ordinary areas; likewise, most prostitution centers are more in inferior areas than high class areas or downtowns (Ebrahimi and Mesgarian, 2008: 24).

Marginalization areas are among talented ones for crime commission. Lack of enough security monitoring, large number of needy and unemployed people, lack of proper lighting in streets and geographical situation all cause than criminals can find a shelter and potential crime generating areas exist whenever such factors exist. The existence of marginal areas can increase pressure on current resources in terms of demands for using pedagogy facilities or it can increase the average rate of illiteracy. If such social problems are treated by planning and radically, they will be emerged in other forms (Khanbashi, marginalization: problems and guidelines).

Organization is an action to legalize marginal communities and restructuring an optimizing marginal areas and preparing their residents to live in a new space. Scientifically and empirically, it is determined that ignoring residents of such areas, destruction and compulsory dispersion are the worst policies in treating with marginalization at least in planning and academic terms. Marginalization is the outcome of incorrect managerial planning and inefficient development. Thus, ignoring policy or coercive treatment indicates the incapability and inefficiency of managers and planners in adopting proper initiatives in this regard. Therefore, these solutions are provided: optimizing marginalization spaces; renovating marginal areas (if optimization is not possible); moving and residing in new locations and providing facilities for returning their homelands.

Social service discussion is too important that several big organizational like Relief Committee, Welfare Organization and Red Crescent along with numerous charities provide such services. In this line, Welfare, Services and Social Contribution Organization has considered these programs in its agenda to perform its missions: identifying, attracting and referring homeless persons and begs, temporary retain and serving social victims in dormitories, providing homeless person in warm houses, identifying and cooperating in residing 
homeless families, providing services to in risk children, providing citizens with services in social service bases, preventing social abnormalities and misbehaviors through training, establishing admission centers (diagnosis centers), and monitoring on identifying and optimizing urban defenseless areas.

\section{Conclusion}

Delinquency is a problem which has involves all communities and they have to allocate huge part of their national wealth and human capital in cubing this social phenomenon. Due to expansion of urbanism and social insecurities propagation in cities, studying security, affecting factors on it and guidelines to foster security in cities have become important. So, urban researchers and experts have addressed the role of urban building in recent decades through adopting initiatives and policies in creating desired environments and proper combination of urban different usages in current urban areas and they have achieved such theories like defensible spaces, crime prevention through environmental designing and environmental criminology. They believe that by using mentioned principles and basics in urban building, one can prevent or mitigate crime occurrence and delinquency in urban environment and to improve citizens' security.

Today, due to the expansion of urbanism and increases in urban abnormal behaviors especially crimes, CPTED has become too important. Environmental planning and designing by recognizing effective spatial characteristics and environmental condition, along with other initiatives, can prevent the occurrence of abnormal behaviors and crimes in urban spaces so that an offender can find less opportunities for criminal acts in parks and public places. In fact, one should say that some social and configurative traits are effective in crime occurrence. By changing the structure of spaces in terms of proper lighting, recreational locations, proper designing of buildings, designing and engineering as well as the attendance of police and using modern monitoring tools in certain periods and a certain location, one can prevent delinquency.

Since security in any society is a complicated problem with different aspects, in procuring security one should not ignore the role of environmental factors. Under such circumstances, urban building system should be considered by approving norms and regulations as well as modifying and complementing services under urban development plans, environmental indicators and creating, keeping and promoting citizens' security feelings. On the other hand, urban management system and planning and managing urban parks by adopting environmental policies especially safety and security and role of environmental factors and traits should be paid attention further.

Today, deviational urbanism has eliminated main locus of cities and has caused marginal areas with unhealthy and illegal homes in poor areas where the most important indicator is crime generation. In this regard, the results of present study indicated that high density of population, low rate of residential, low rooms, low area of homes along with material with low quality and resistance are the main traits of such neighborhoods. Also, the findings show that poverty, unemployment, lower income and other factors encourage people to false jobs, illicit drug sale, prostitution and other social corruptions compared to other regions and, as a result, increases in crime generation in marginal areas.

A proposed guideline is to create single urban management to control constructions and to increase the physical aspects of the city; security and law enforcement consideration confirmed by police in approving house and urban building plans; prevention of emigration to cities; improving deprived areas and creating job opportunities for their people; creating training and recreational centers in deprived areas especially programs for teenagers and youngsters; expanding welfare services through municipalities on water, power, telecommunications and so on in these areas; fostering and enhancing police attendance in such areas and using modern control devices.

Considering conducted studies and findings of present paper, one can conclude that by changing the structure of urban ambience like optimizing marginal areas, adequate lighting in alleys and streets, recreational centers, proper designing on buildings, planned urban building and proper designing and engineering of environment and landscapers, municipality can prevent crimes occurrence. Likewise, by distributing balanced different usages in cities, municipality can improve social monitoring in non-crowded areas on the one hand and to decrease over-density of population and activities in crowd areas of the cities on the hand; in this way, municipality can prevent crimes occurrence.

\section{References}

Afzali, R. (2013). studying the legal aspects of urban security and the performance of officials in organizing citizen's security problems. Human Geographical Researches, 4.

Akhundi, E. (1996). architecture reflects human's image of the world. Public Culture Quarterly.

Alsan, M. (2008). multi-entity urban crime prevention. Crime Prevention Studies Journal, 9. 
Bahrayni, H., \& Tajbakhsh, G. (1998). the scope of territory in urban designing. Beautiful Arts Publications, University of Tehran.

Clark, R. (1980). crime prevention situations. University of Chicago.

Cleveland, G. (1976). second generation of environmental designing, urban designing anti-virus.

Ebrahimi, A., \& Mesgaryan, E. (2008). economic pathology of marginal areas and its association with crimes. Remedy and Education Journal, 78.

Ebrahimi, Sh. (2011). preventive criminology. Mizan, Publications.

Ehsani, B. (2004). the role of spatial designing in crime prevention.

Felisner, D. (2004). crime prevention through environmental designing and Police affairs office, translated by Leila Asl Alizadeh, Law Enforcement Knowledge Quarterly Journal, 1.

Ghalibaf, M., Ansarizadeh, S., \& PArhiz, F. (2010). studying and analyzing the role of crime generating locus in urban crimes. Municipalities, 100.

Ghurchi Beigi, M. (2007). CPTED applied guidelines for crime prevention in residential areas. Jurisprudence and Laws, 15.

Hussieni, F. (2008). studying and providing configuration/functional effective indicators on promoting urban public places security.

Jaccobs, G. (1961). death and life in US metropolitans.

Kalantary, M. (2001). crime geographical study in Tehran boroughs, Geography doctoral thesis. Urban Planning, Geography School, University of Tehran.

Kalantary, M., \& Tavakoli. (2007). identifying and analyzing urban crime generating locus. Crime Prevention Studies Quarterly Journal, Prevention Police Journal, 2.

Kamyar, Gh. (2006). urban rights and urban building. Majd Publications.

Khanbashi, M. (n. d.). marginalization: problems and guidelines.

Mortezaei, R. (2002). designing the tools to combat vandalism in urban environment. Municipalities Journal, 25.

Najafiabrandabadi, E. (2004). discussion on criminal sciences.

Najafiabrandabadi, E., \& Hashem Beigi, H. (1998). criminology encyclopedia. University of Tehran, Publication.

Pourjafar, M. (2008). promoting environmental security and reducing urban crimes by emphasis on CPTED. Engineering International Journal, 19.

Pourjafar, M. R., \& Sadeghi, E. (2008). principles of objective designing of urban indicators designing. City Identity Journal, 3.

Rahmat, M. (2006). the role of environmental in crime prevention by studying the ideas of authors. Govah Legal Journal, $8 \& 9$.

Salehi, A. (2009). the role urban building (environmental theory) in preventing abnormal urban behaviors. Fine Arts, Architecture and Urban Building Journal, 39.

Slaehi, A. (2008). environmental characteristics of secure urban spaces. Architecture and Urban Building Studies Center.

Suleimanpour, M. (2005). the relationship between social security and making crime environment insecure for crime prevention, Tehran, Police Social Directorate.

\section{Copyrights}

Copyright for this article is retained by the author(s), with first publication rights granted to the journal.

This is an open-access article distributed under the terms and conditions of the Creative Commons Attribution license (http://creativecommons.org/licenses/by/3.0/). 